\title{
Mitral Valve Regurgitant Fraction
}

National Cancer Institute

\section{Source}

National Cancer Institute. Mitral Valve Regurgitant Fraction. NCI Thesaurus. Code

C127578.

A quantitative measurement of the amount of retrog rade blood flow across the orifice of the mitral valve expressed as a percentage of the anterograde flow. 